\title{
Pre-treatment with $\beta$ blockers and the frequency of hypokalaemia in patients with acute chest pain
}

\author{
ELLIOTT SIMPSON, * J CHRISTINE RODGER, $†$ S MAHENDRA RAJ, $†$ \\ CHRIS WONG, $\dagger$ LAURA WILKIE, $\ddagger$ CHRISTOPHER ROBERTSON $\ddagger$ \\ From the Departments of ${ }^{\star}$ Biochemistry and $\nmid$ Medicine, Monklands District General Hospital, Airdrie, \\ Lanarkshire and $\ddagger$ Department of Mathematics, University of Strathclyde, Glasgow
}

SUMMARY Plasma potassium concentration was measured at admission in 1234 patients who presented with acute chest pain. One hundred and ninety five patients were on $\beta$ blockers before admission. The potassium concentrations of patients admitted early (within four hours of onset of symptoms) were compared with those admitted later (4-18 hours after onset of symptoms). There was a transient fall in plasma potassium concentrations in patients not pre-treated with $\beta$ blockers. This was not seen in patients who had been on $\beta$ blockers before admission. Nonselective $\beta$ blockers were more effective than cardioselective agents in maintaining concentrations of plasma potassium.

These findings suggest a mechanism for the beneficial effects of $\beta$ blockers on morbidity and mortality in acute myocardial infarction.

There is speculation that the hypokalaemia of myocardial infarction is adrenaline induced and that $\beta$ blockade, given early, may be effective in preventing or attenuating it. ${ }^{1}$ In the present study we investigated whether pre-treatment with $\beta$ blockers can maintain plasma potassium concentrations and reduce the frequency of hypokalaemia in patients admitted with ischaemic chest pain.

\section{Patients and methods}

We measured the initial concentration of plasma potassium in 1234 consecutive patients at admission to the cardiac care unit. The plasma was separated with minimum delay (less than one hour) and analysed by flame photometry. All patients had acute chest pain: 432 had evidence of acute myocardial infarction and the remainder were considered to have acute myocardial ischaemia. Before admission, 126

Requests for reprints to Dr J Christine Rodger, Monklands District General Hospital, Airdrie ML6 0JS, Lanarkshire.

Accepted for publication 19 May 1987 patients were on a $\beta$ blocking agent, 270 were on a diuretic, and an additional 69 were on both a $\beta$ blocker and a diuretic; the remaining patients were on neither of these drugs. No patient was given a $\beta$ blocker in hospital before the initial blood specimen was taken.

The case records of 1010 of the patients were examined retrospectively to establish the times from onset of symptoms to sampling. There is no reason to believe that these patients are unrepresentative of the total group.

\section{Statistical methods}

We used factorial analysis of variance models ${ }^{2}$ to investigate the effects of the following factors on plasma potassium concentrations: $(a)$ the nature of the presenting condition (that is infarction or ischaemia); (b) the time from onset of symptoms to sampling; $(c)$ the presence or absence of diuretics; and $(d)$ the presence or absence of a $\beta$ blocker. Because the distribution of potassium values was positively skewed we used $\log$ potassium values to calculate confidence intervals and tests of sig- 
Table 1 Concentration of plasma potassium on admission in patients with acute chest pain

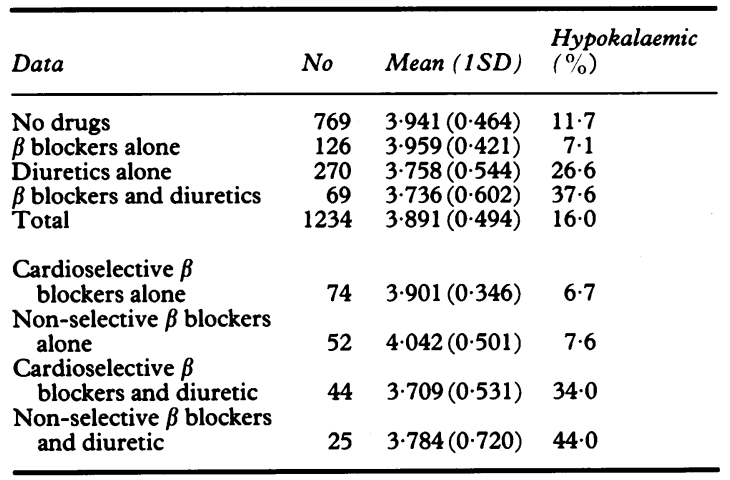

nificance. Because this produced very similar results to those obtained using the raw data untransformed means and standard deviations of plasma potassium values $(\mathrm{mmol} / \mathrm{l})$ are given in the tables. The differences in means given in the text are derived from the factorial analysis with log transformation, and are thus not identical to the differences obtained by subtraction of the arithmetic means given in the tables.

We used a logit model for a parallel analysis of the proportion of patients with hypokalaemia on admission; this is the standard method for investigating the effects of multiple factors on proportions. ${ }^{3}$

\section{Results}

Table 1 sets out the results for all 1234 patients taking no account of the time from onset of symptoms to sampling and analysing the infarction and ischaemic groups together. These results show that there was no significant difference between the mean plasma potassium concentrations or the frequency of hypokalaemia (potassium $<3.5 \mathrm{mmol} / \mathrm{l}$ ) in patients on $\beta$ blockers alone (both cardioselective and nonselective) and in those on no drug treatment at the time of admission. Neither was there any significant difference in the mean potassium concentrations in patients on cardioselective and non-selective $\beta$ blocking agents. Patients on diuretics had a significantly lower mean potassium (mean difference $0.18 \mathrm{mmol} / 1,95 \%$ confidence interval (CI) 0.11 to $0.26, \mathrm{p}<0.001)$ and a significantly higher frequency of hypokalaemia (mean difference $15 \%, 95 \%$ CI 9 to $21 \%, p<0.001)$ than those on no drug treatment. There was no significant difference between the mean potassium concentrations in patients on both a $\beta$ blocker and a diuretic and in those on a diuretic alone. Mean potassium concentrations in patients on a cardioselective agent and a diuretic were not significantly different from those in patients on a non-selective agent and a diuretic.

In table 2 the results for patients with acute myocardial infarction and myocardial ischaemia are considered separately. The mean plasma potassium concentrations in patients with myocardial infarction and those with myocardial ischaemia were not significantly different. In the absence of drug treatment, however, the frequency of hypokalaemia is higher in the infarct group than in the ischaemic group (mean difference $5 \%, 95 \%$ CI $0 \%$ to $9 \%$, $\mathrm{p}<0.07)$. Thus when no account was taken of the time from onset of symptoms to sampling, no significant effect of pre-treatment with $\beta$ blockers on the mean potassium concentrations or on the frequency of hypokalaemia was demonstrated; this held for patients on diuretics as well as those on no drug treatment. Pre-treatment with diuretics is associated

Table 2 Concentration of plasma potassium on admission in patients with acute myocardial infarction and patients with myocardial ischaemia

\begin{tabular}{|c|c|c|c|c|c|c|}
\hline \multirow[b]{2}{*}{ Data } & \multicolumn{3}{|c|}{ Myocardial infarction } & \multicolumn{3}{|c|}{ Myocardial ischaemia } \\
\hline & No & Mean (1SD) & Hypokalaemia (\%) & No & Mean (1SD) & Hypokalaemia $(\%)$ \\
\hline $\begin{array}{l}\text { No drugs } \\
\beta \text { blockers alone } \\
\text { Diuretics alone } \\
\beta \text { blockers and diuretics } \\
\text { Total }\end{array}$ & $\begin{array}{r}305 \\
42 \\
60 \\
25 \\
432\end{array}$ & $\begin{array}{l}3.942(0.483) \\
3.980(0.510) \\
3.826(0.704) \\
3.724(0.522) \\
3.917(0.526)\end{array}$ & $\begin{array}{l}14 \cdot 4 \\
16 \cdot 6 \\
31 \cdot 6 \\
36 \cdot 0 \\
18 \cdot 3\end{array}$ & $\begin{array}{r}464 \\
84 \\
210 \\
44 \\
802\end{array}$ & $\begin{array}{l}3.940(0.452) \\
3.948(0.371) \\
3.739(0.489) \\
3.743(0.649) \\
3.877(0.476)\end{array}$ & $\begin{array}{r}9 \cdot 9 \\
2 \cdot 3 \\
25 \cdot 2 \\
38 \cdot 6 \\
14 \cdot 7\end{array}$ \\
\hline $\begin{array}{l}\text { Cardioselective } \beta \text { blockers alone } \\
\text { Non-selective } \beta \text { blockers alone }\end{array}$ & $\begin{array}{l}24 \\
18\end{array}$ & $\begin{array}{l}3.925(0.452) \\
4.055(0.585)\end{array}$ & $\begin{array}{l}16 \cdot 6 \\
16 \cdot 6\end{array}$ & $\begin{array}{l}50 \\
34\end{array}$ & $\begin{array}{l}3.890(0 \cdot 286) \\
4.035(0 \cdot 461)\end{array}$ & $\begin{array}{l}2 \cdot 0 \\
2 \cdot 9\end{array}$ \\
\hline $\begin{array}{l}\text { Cardioselective } \beta \text { blockers and } \\
\text { diuretic }\end{array}$ & 15 & $3.753(0.530)$ & $26 \cdot 6$ & 29 & $3.686(0.539)$ & $37 \cdot 9$ \\
\hline $\begin{array}{l}\text { Non-selective } \beta \text { blockers and } \\
\text { diuretic }\end{array}$ & 10 & $3.680(0.534)$ & $50 \cdot 0$ & 15 & $3.853(0.832)$ & $40 \cdot 0$ \\
\hline
\end{tabular}


Table 3 Concentration of plasma potassium on admission in patients with acute chest pain. Values for those admitted within 4 hours of onset of symptoms are compared with values for those admitted 4 to 18 hours after onset

\begin{tabular}{|c|c|c|c|c|c|c|}
\hline \multirow[b]{2}{*}{ Data } & \multicolumn{3}{|c|}{ Admitted within 4 hours } & \multicolumn{3}{|c|}{ Admitted 4-18 hours } \\
\hline & No & Mean (1SD) & Hypokalaemic (\%) & No & Mean (1SD) & Hypokalaemic (\%) \\
\hline $\begin{array}{l}\text { No drugs } \\
\beta \text { blockers alone } \\
\text { Diuretics alone } \\
\beta \text { blockers and diuretics } \\
\text { Total }\end{array}$ & $\begin{array}{r}351 \\
61 \\
143 \\
39 \\
594\end{array}$ & $\begin{array}{l}3.879(0.464) \\
4.068(0.507) \\
3.709(0.542) \\
3.784(0.693) \\
3.851(0.514)\end{array}$ & $\begin{array}{r}16 \cdot 5 \\
3 \cdot 2 \\
25 \cdot 8 \\
38 \cdot 4 \\
18 \cdot 9\end{array}$ & $\begin{array}{r}215 \\
62 \\
107 \\
32 \\
416\end{array}$ & $\begin{array}{l}4.011(0.389) \\
3.909(0.352) \\
3.769(0.476) \\
3.731(0.530) \\
3.912(0.434)\end{array}$ & $\begin{array}{r}5 \cdot 1 \\
8 \cdot 0 \\
25 \cdot 2 \\
28 \cdot 1 \\
12 \cdot 5\end{array}$ \\
\hline
\end{tabular}

Table 4 Concentration of plasma potassium on admission in patients with acute myocardial infarction. Values for those admitted within 4 hours of onset of symptoms are compared with values for those admitted 4 to 18 hours after onset

\begin{tabular}{|c|c|c|c|c|c|c|}
\hline \multirow[b]{2}{*}{ Data } & \multicolumn{3}{|c|}{ Admitted within 4 hours } & \multicolumn{3}{|c|}{ Admitted 4-18 hours } \\
\hline & No & Mean (1SD) & Hypokalaemic (\%) & No & Mean (1SD) & Hypokalaemic (\%) \\
\hline $\begin{array}{l}\text { No drugs } \\
\beta \text { blockers alone } \\
\text { Diuretics alone } \\
\beta \text { blockers and diuretics } \\
\text { Total }\end{array}$ & $\begin{array}{r}163 \\
18 \\
30 \\
14 \\
225\end{array}$ & $\begin{array}{l}3.875(0.515) \\
4.183(0.697) \\
3.540(0.454) \\
3.792(0.782) \\
3.850(0.560)\end{array}$ & $\begin{array}{l}20 \cdot 2 \\
11 \cdot 1 \\
30 \cdot 0 \\
42 \cdot 8 \\
22 \cdot 2\end{array}$ & $\begin{array}{r}80 \\
24 \\
26 \\
14 \\
144\end{array}$ & $\begin{array}{l}4.007(0.406) \\
3.845(0.398) \\
3.942(0.656) \\
3.807(0.451) \\
3.949(0.465)\end{array}$ & $\begin{array}{r}7 \cdot 5 \\
16 \cdot 6 \\
30 \cdot 7 \\
14 \cdot 2 \\
13 \cdot 9\end{array}$ \\
\hline
\end{tabular}

Table 5 Concentration of plasma potassium on admission in patients with acute myocardial ischaemia. Values for those admitted within 4 hours of onset of symptoms are compared with values for those admitted 4 to 18 hours after onset

\begin{tabular}{|c|c|c|c|c|c|c|}
\hline \multirow[b]{2}{*}{ Data } & \multicolumn{3}{|c|}{ Admitted within 4 hours } & \multicolumn{3}{|c|}{ Admitted 4-18 hours } \\
\hline & No & $\operatorname{Mean}(1 S D)$ & Hypokalaemic (\%) & No & Mean (1SD) & Hypokalaemic (\%) \\
\hline $\begin{array}{l}\text { No drugs } \\
\beta \text { blockers alone } \\
\text { Diuretics alone } \\
\beta \text { blockers and diuretics } \\
\text { Total }\end{array}$ & $\begin{array}{r}188 \\
43 \\
113 \\
25 \\
369\end{array}$ & $\begin{array}{l}3.883(0.416) \\
4.020(0.403) \\
3.754(0.556) \\
3.780(0.655) \\
3.852(0.485)\end{array}$ & $\begin{array}{r}13 \cdot 2 \\
0 \cdot 0 \\
24 \cdot 7 \\
36 \cdot 0 \\
16 \cdot 8\end{array}$ & $\begin{array}{r}135 \\
38 \\
81 \\
18 \\
272\end{array}$ & $\begin{array}{l}4.014(0.381) \\
3.950(0.319) \\
3.713(0.391) \\
3.672(0.589) \\
3.893(0.416)\end{array}$ & $\begin{array}{r}3 \cdot 7 \\
2 \cdot 6 \\
23 \cdot 4 \\
38 \cdot 8 \\
11 \cdot 8\end{array}$ \\
\hline
\end{tabular}

with a significant reduction in plasma potassium and a significant increase in the frequency of hypokalaemia on admission.

Table 3 examines the effect of time from onset of symptoms to sampling, but without separate analysis of acute myocardial infarction and ischaemia. In patients on no drug treatment those admitted within four hours of symptoms had a lower mean plasma potassium concentration (mean difference $0.13 \mathrm{mmol} / 1,95 \%$ CI 0.07 to 0.22 , $\mathrm{p}<0.001$ ) and a higher frequency of hypokalaemia (mean difference $11 \%, 95 \mathrm{CI} 6$ to $16, \mathrm{p}<0.01$ ) than those admitted after four hours. A rise in plasma potassium with time may thus be inferred. A rise in mean plasma potassium with time may similarly be inferred in patients pre-treated with diuretics alone but not in patients pre-treated with $\beta$ blockers. In patients admitted within four hours of the onset of symptoms, pre-treatment with $\beta$ blockers was associated with a higher mean plasma potassium (mean difference $0.14 \mathrm{mmol} / 1,95 \%$ CI 0.05 to 0.23 , $\mathrm{p}<0.01)$ and a lower frequency of hypokalaemia than no drug treatment (mean difference 16\%, 95\% CI 4 to $45, p<0.01$ ).

Tables 4 and 5 present the results for infarct and ischaemic patients and fig 1 shows the differences in mean plasma potassium concentrations.

For patients with myocardial infarcts who were admitted within four hours the mean potassium concentration was significantly higher in those on $\beta$ blockers than in those on no drugs, and patients on both a $\beta$ blocker and a diuretic had a higher mean potassium concentration than those on diuretics alone (mean difference $0.27 \mathrm{mmol} / 1,95 \%$ CI 0.05 to 

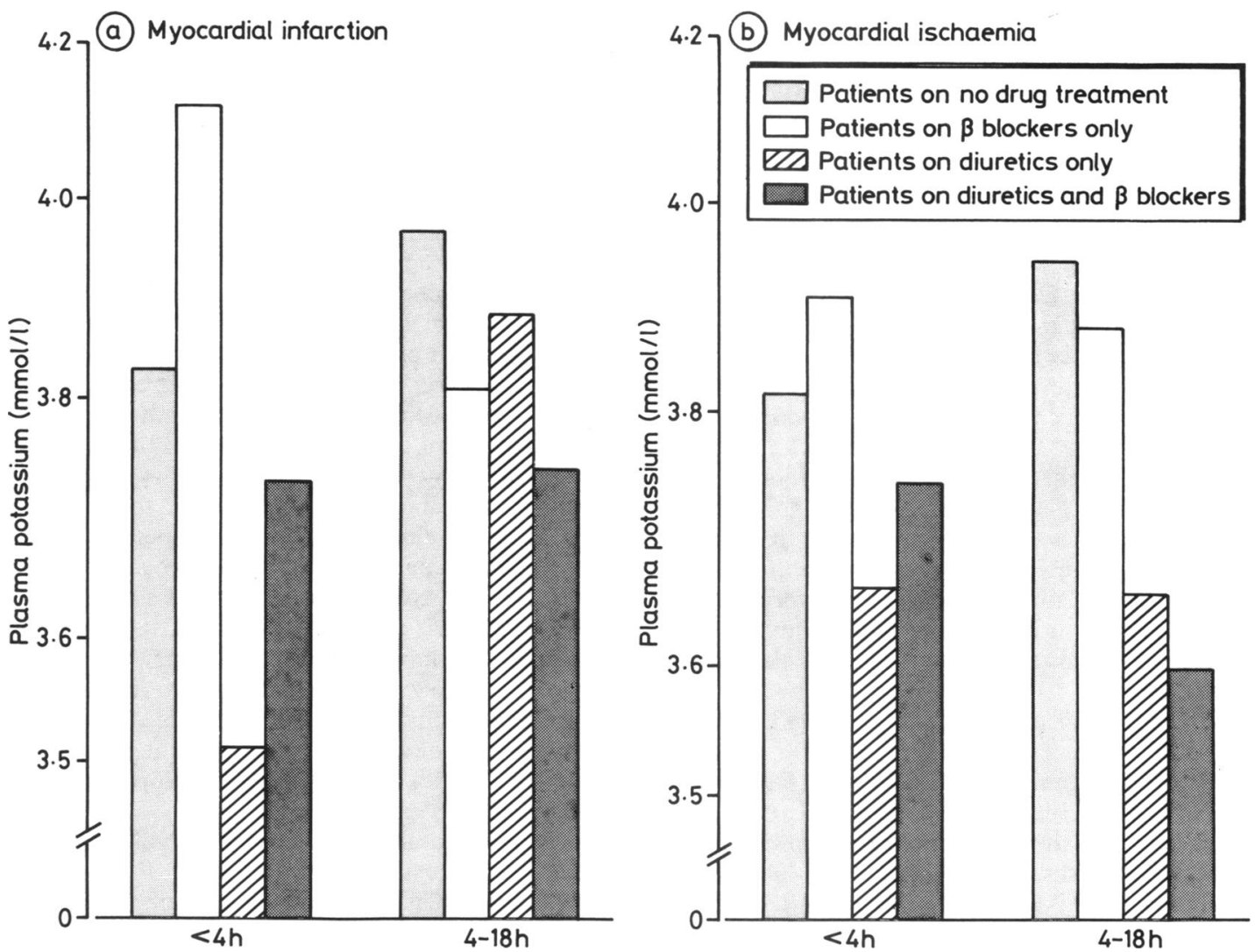

Fig 1 Concentrations of plasma potassium on admission in patients admitted within four hours of onset of symptoms and patients admitted 4-18 hours after onset. (a) In patients with acute myocardial infarction and $(b)$ in patients with myocardial ischaemia.

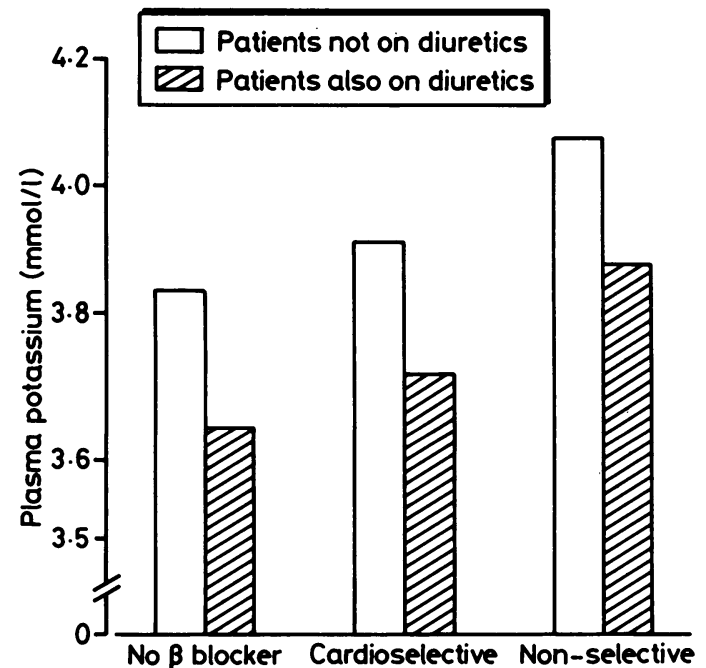

Fig 2 Concentrations of plasma potassium on admission in patients admitted with acute chest pain within four hours of onset of symptoms and pretreated cardioselective or non-selective $\beta$ blockers.
$0.5, \mathrm{p}<0.05)$. For ischaemic patients admitted within four hours, the mean plasma potassium in those on $\beta$ blockers was also higher than in those on no drugs, but this difference was not significant (mean difference $0.10 \mathrm{mmol} / 1,95 \%$ CI -0.03 to $0 \cdot 23, \mathrm{p}<0 \cdot 15)$. For both infarct and ischaemic patients admitted 4-18 hours after onset, the mean potassium concentration in patients on $\beta$ blockers was not significantly different from those on no drugs.

Figure 2 compares the influence of cardioselective and non-selective $\beta$ blockers on mean plasma potassium concentrations. No significant effect of cardioselective $\beta$ blockers on mean plasma potassium was demonstrated. The effect of non-selective $\beta$ blockers on mean plasma potassium concentration was evident in patients admitted within four hours of onset of symptoms. In this group the mean potassium concentration in patients on non-selective $\beta$ blockers was significantly higher than in those on no drugs and similarly those on non-selective $\beta$ blockers and diuretics had a higher mean potassium than those on diuretics alone (mean difference $0.25 \mathrm{mmol} / 1,95 \%$ CI 0.08 to $0.43, \mathrm{p}<0.01$ ). 


\section{Discussion}

Although the effect on plasma potassium concentrations of intravenous $\beta$ blockade introduced after the onset of acute myocardial infarction has been studied, ${ }^{45}$ little is known about what happens to plasma potassium concentrations in patients who are already on $\beta$ blockers at the time of their infarction.

In analysing our findings we have combined results from patients with acute myocardial infarction and myocardial ischaemia. We consider that this approach is justified, firstly because there was no significant difference between the mean plasma potassium concentrations for infarct and ischaemic patients in any of the subgroups, and secondly because, though the frequency of hypokalaemia in our ischaemic patients was less than that in infarct patients, it was not negligible. The frequency of hypokalaemia in patients admitted with ischaemic chest pain has not been reported before; however, the frequency of hypokalaemia in acute myocardial infarction in this study was similar to that reported by others. ${ }^{67}$

The hypokalaemia that was found was mild in most instances, and only $2 \%$ of patients had plasma potassium concentrations on admission of $<3.0 \mathrm{mmol} / \mathrm{l}$. But plasma potassium concentrations between 3.0 and $3.5 \mathrm{mmol} / 1$ can predispose to ventricular arrhythmias, ${ }^{8}$ and mild hypokalaemia cannot be dismissed as clinically unimportant.

Table 1 shows that, if no account is taken of the time from onset of symptoms to sampling, it is not possible to demonstrate an effect of $\beta$ blockers on plasma potassium concentrations. Provided that time is taken into account, as in table $3, \beta$ blockers can be shown to maintain potassium concentrations and reduce the frequency of hypokalaemia. This effect, however, is evident only shortly after the onset of symptoms (in this study within four hours). There are two possible explanations for this. One is that as the hypokalaemia is transient, lasting for hours only and resolving spontaneously, ${ }^{9}$ the beneficial effect of pre-treatment with $\beta$ blockers can only be expected during the early stages when the plasma potassium would otherwise be low. The other possible explanation is that plasma concentrations of the $\beta$ blockers may be lower in patients who are admitted later.

Our findings are consistent with the hypothesis that the hypokalaemia of acute myocardial infarction is adrenaline induced. Our findings also have practical implications: they suggest that should myocardial infarction or ischaemia occur in patients already on a $\beta$ blocker (whether for hypertension or after infarction) normokalaemia is more likely to be maintained, and ventricular arrhythmias may be thus less likely to occur than in patients who are not similarly pre-treated.

In the only previous study that is directly comparable to ours pre-treatment with $\beta$ blockers had no effect on plasma potassium concentrations in a group of nine patients with acute myocardial infarction. ${ }^{5}$ In the light of our present findings, this was to be expected as the mean time from the onset of symptoms to admission in this group was greater than four hours.

Others have looked at the effects on potassium concentrations of intravenous $\beta$ blockers introduced after the onset of myocardial infarction. ${ }^{45}$ The design of these studies is different from ours and the practical implications of the results are also different. None the less, these two approaches do lead to the same broad conclusion, that is that $\beta$ blockade can favourably influence potassium concentrations in patients with acute myocardial infarction. Because Nordrehaug et al used a definition of hypokalaemia $(\leqslant 3.5 \mathrm{mmol} / 1)^{4}$ that is wider than usual $(<3.5 \mathrm{mmol} / \mathrm{l})$ their study may be open to criticism. Also we have been unable to reproduce the statistical results reported in their table II: in particular we did not achieve any significant probabilities smaller than $5 \%$ when we used the appropriate two tailed Fisher's exact test.

We showed that non-selective $\beta$ blockers were more effective than cardioselective $\beta$ blockers in maintaining plasma potassium concentrations. This is in keeping with the results of experimental studies which showed that adrenaline-induced hypokalaemia may be prevented by non-selective $\beta$ blockade and attenuated by cardioselective $\beta$ blockade. ${ }^{10}$

Studies in normal volunteers have shown that infused adrenaline and pre-treatment with diuretics have additive hypokalaemia effects. ${ }^{11}$ In keeping with this additive effect, we found that $\beta$ blockers did, to some extent, maintain plasma potassium in patients who were also on diuretics. Overall, however, the frequency of hypokalaemia in patients on both $\beta$ blockers and diuretics in this study was substantial, and concurrent $\beta$ blockade cannot be regarded as an adequate protection against diuretic induced hypokalaemia. This is exemplified by the frequency of hypokalaemia reported in patients on proprietary preparations of combined $\beta$ blockers and diuretics, ${ }^{12} 13$ and, indeed, in this study nine (47\%) of 19 patients on such proprietary preparations were hypokalaemic.

We were able to show that pre-treatment with $\beta$ blockers can maintain plasma potassium concentrations and attenuate hypokalaemia in patients with acute ischaemic chest pain. These results suggest one possible mechanism for the beneficial effects of $\beta$ blockers on morbidity ${ }^{14}$ and mortality ${ }^{14}{ }^{15}$ in acute 
myocardial infarction. They also suggest a possible mechanism for the long term reduction in mortality (reinfarction and sudden death) that has been observed in patients on prophylactic $\beta$ blockade after myocardial infarction. ${ }^{16} 17$

LW was supported by a grant from Astra Pharmaceuticals Ltd.

\section{References}

1 Anonymous. Adrenaline and potassium: everything in flux. Lancet 1983;ii:1401-3.

2 Armitage P. Statistical methods in medical research. London: Blackwell Scientific Publications, 1971.

3 Cox DR. The analysis of binary data. London: Chapman \& Hall, 1970.

4 Nordrehaug JE, Johannessen K-A, von der Lippe G, Sederholm M, Grøttum P, Kjekshus J. Effect of timolol on changes in serum potassium concentration during acute myocardial infarction. $\mathrm{Br}$ Heart $\mathrm{J}$ 1985;53:388-93.

5 Jardine RM, Obel IWP, Smith AM. Intravenous acebutolol raises serum potassium in acute myocardial infarction. Eur Heart $J$ 1986;7:140-5.

6 Dyckner T, Helmers C, Lundman T, Wester PO. Initial serum potassium level in relation to early complications and prognosis in patients with acute myocardial infarction. Acta Med Scand 1975;197:207-10.

7 Solomon RJ, Cole AG. Importance of potassium in patients with acute myocardial infarction. Acta Med Scand [Suppl] 1981;647:87-93.

8 Stewart DE, Ikram H, Espiner EA, Nicholls MG. Ar- 
rhythmogenic potential of diuretic induced hypokalaemia in patients with mild hypertension and ischaemic heart disease. $\mathrm{Br}$ Heart $J$ 1985;54:290-7.

9 Rodger JC, Simpson E, Rolton HA, Reid W. The hypokalaemia of acute myocardial infarction. Ann Clin Biochem 1986;23:204-5.

10 Struthers AD, Reid JL, Whitesmith R, Rodger JC. The effects of cardioselective and non-selective betaadrenoceptor blockade on the hypokalaemic and cardiovascular response to adrenomedullary hormones in man. Clin Sci 1983;65:143-7.

11 Struthers AD, Whitesmith R, Reid JL. Prior thiazide diuretic treatment increases adrenaline-induced hypokalaemia. Lancet 1983;i:1358-61.

12 Odugbesan O, Chesner IM, Bailey G, Barnett AH Hazards of combined beta-blocker/diuretic tablets. Lancet 1985;i:1221-2.

13 Rodger JC, Simpson E, Raj SM. Hazards of combined beta-blocker/diuretic. Lancet 1985;i:1395.

14 Yusuf S, Sleight P, Rossi P, et al. Reduction in infarct size, arrhythmias and chest pain by early intravenous beta-blockade in suspected acute myocardial infarction. Circulation 1983;67 (suppl I):I-32-41.

15 ISIS-1 (First International Study of Infarct Survival) Collaborative Group. Randomised trial of intravenous atenolol among 16027 cases of suspected acute myocardial infarction: ISIS-1. Lancet 1986;ii:57-66.

16 Beta-blocker Heart Attack Trial Research Group. A randomised trial of propranolol in patients with acute myocardial infarction: 1 . Mortality results. $J A M A$ 1982;247:1707-14.

17 The Norwegian Multicentre Study Group. Timolol induced reduction in mortality and reinfarction in patients surviving acute myocardial infarction. $N$ Engl J Med 1981;304:801-7. 